Fecha de recepción: marzo 2010

Fecha de aceptación: marzo 2011

Versión final: septiembre 2013

\section{La naturaleza estratégica del proceso de branding}

Elda Llamas *

\begin{abstract}
Resumen: El branding, anglicismo con el que se denomina a la creación y gestión estratégica de una marca, cobró notoriedad en la década del '90 incorporándose al debate académico y a la actividad profesional del campo disciplinar del diseño y el marketing. En ese trayecto provocó cierta confusión respecto a la naturaleza -a veces estratégica y a veces táctica- de la actividad. Este hecho da lugar a la reflexión teórica sobre el nuevo territorio y a explorar la actividad que rodea a la construcción de una marca, en un intento por descubrir perspectivas teóricas que ayuden a comprender el proceso. Al hacerlo, se examina la noción de marca como sistema bipolar de producción y proyección de imágenes, y se exploran las fases del proceso de desarrollo de la marca en paralelo al proceso de planeamiento estratégico. Finalmente, se analiza la influencia que recibe el proceso de diferentes escuelas de pensamiento estratégico para descubrir las nuevas fronteras que atraviesa este paradigma.
\end{abstract}

Palabras claves: branding - construcción marcaria - estrategia de marca - gestión de diseño de marca - imagen visual de la marca - marketing - visión de marca.

[Resúmenes en inglés y portugués en la página 228]

${ }^{(*)}$ Licenciada en Comercialización (UADE). Fundadora de Ideobrand. Docente de la Facultad de Diseño y Comunicación de la Universidad de Palermo y de la Universidad de Ciencias Empresariales y Sociales.

La noción de branding, anglicismo con el que se denomina a la actividad que rodea a la creación y gestión estratégica de una marca, emergió hacia fines de la década del '90 incorporándose como temática al debate y a la actividad profesional del campo disciplinar del diseño y el marketing. Con frecuencia, las nuevas temáticas se originan en la práctica profesional antes que en el ámbito académico, y en ese proceso suelen provocar cierta confusión en la perspectiva que adopta cada disciplina. No eximidos de esta regla, diseñadores y profesionales en marketing con frecuencia se refieren a la actividad de branding, y en particular a la estrategia de marca, partiendo de concepciones no coincidentes. Este hecho da lugar a la reflexión teórica sobre el nuevo territorio y a explorar la actividad que rodea a la construcción de una marca en un intento por descubrir perspectivas teóricas que ayuden a comprender la naturaleza de este proceso. Antes de revisar el espectro de actividades que se consideran parte del proceso de branding en la práctica profesional, es conveniente revisar en qué consiste exactamente este concepto. Aunque 
no se cuenta con una concepción única del término, su etimología señala que proviene del vocablo brand que en inglés significa marca, motivo por el cual resulta interesante realizar una breve revisión del trayecto atravesado por la marca a través de su recorrido histórico más reciente.

Las marcas, como fenómeno de la Modernidad y de la sociedad industrial, surgieron desde el campo disciplinar del derecho al promulgarse las leyes de propiedad intelectual en los Estados Unidos y en el Reino Unido en los años 1870 y 1875 respectivamente. El registro de la marca, como objeto de propiedad intelectual, respondía a la necesidad de los fabricantes de identificar los bienes que producían para distinguirlos de aquellos elaborados por sus competidores. En esa época el diseño gráfico realizó sus primeros aportes al diseñar el -en aquel entonces llamado- isologotipo, que más adelante evolucionaría en complejidad para convertirse en un sistema de identidad visual, utilizado con el fin de generar familiaridad y reconocimiento en el medio de una multitud de productos competidores. Progresivamente, a través de décadas sucesivas, las marcas relegaron a un segundo plano la función de identificación, otorgándole preeminencia a la función de significación. Al hacerlo, se trasciende la referencia a las características funcionales del producto para construir un plano imaginario, que es oportuno reconocer, recibió un significativo aporte de la publicidad.

Según el Diccionario de Negocios (2009), branding es:

...el proceso completo involucrado en la creación de un nombre singular y una imagen para un producto (bien o servicio) en la mente del consumidor, a través de campañas de publicidad que utilicen un tema consistente. El branding tiene el propósito de establecer una presencia significativa y diferenciada en el mercado para atraer y retener consumidores fieles.

$\mathrm{Al}$ analizar esta definición, es importante observar que hace referencia a un 'proceso' que tiene por fin proyectar una 'imagen mental' mediante un uso consistente de la publicidad vinculada a un nombre marcario (y podríamos agregar otros recursos de diseño y comunicación). Esta explicitación de un 'proceso de planeamiento' implica que no son las acciones (tácticas) de marketing la sustancia del branding sino su naturaleza estratégica que le otorga a la marca una dirección a futuro a través de la formulación de un plan. De otro modo, cualquier acción de marketing podría consideranse una acción de branding por el solo hecho de tener por destinataria a una marca en particular. A diferencia de acciones aisladas -aunque pudieran ser creativas y aún efectivas- el propósito del branding es crear y añadir valor al producto o servicio a través de un sistema de representación de imágenes consistente que se expresa por medio de recursos visuales y de comunicacíón.

El sistema productor, de forma análoga a un proyector que reproduce una imagen sobre una pantalla, opera como generador de una categoría diferente de representaciones constituida por las imágenes mentales que son almacenadas en la memoria inscripta en el sistema preconciente o inconsciente de la psiquis. Se tratan de imágenes mentales que remiten y se traducen en recuerdos e impresiones que pueden ser activados por la palabra o por ciertas imágenes visuales, influyendo así sobre la percepción del mundo exterior y la imagen de sí que posee el individuo, y como resultado de ello, sobre su conducta.

Cabe señalar que, aunque es cierto que no se puede concebir una marca sin la imagen gráfica que la identifique, tampoco se puede suponer que la identidad visual por sí sola constituye el 
motor simbólico que produce la totalidad de las imágenes mentales a las que la marca remite. Consecuentemente, es válido afirmar que el rasgo saliente de la noción de branding es el hecho que se trata de un proceso que apunta a crear un sistema de representación de imágenes articulando un sistema productor de imágenes con un sistema de representación mental. El propósito ulterior de dicho sistema es crear una experiencia que por efecto de acumulación produzca una imagen mental traducida en reconocimiento y en una gestalt de asociaciones distintivas ante el público al que se dirige. Dicho de otra manera, la naturaleza lingüística, icónica y cromática de la marca confluye en la imagen visual que opera como vehículo portador del conjunto de valores simbólicos que la marca propone a un público predeterminado con el fin de diferenciarse de sus competidores y, generar reconocimiento y recordación.

En definitiva, la condición que determina la existencia de un proceso de branding es que toda acción vinculada a la creación y gestión de la marca responda a un plan predeterminado en el que se defina el sistema de asociaciones que la marca se propone representar. El hecho implica un proceso de planeamiento y ello en principio le otorga la condición de estrategia, al menos desde la perspectiva más tradicional de la noción que se analizará más adelante.

Pero cabe preguntarse en esta instancia ¿qué involucra con exactitud el proceso de desarrollo de una marca? La concepción de este proceso ha sufrido modificaciones a través del tiempo como consecuencia de un cambio de paradigma que tuvo lugar en el campo de las ciencias empresariales. El modelo clásico, precursor del campo del branding, concebía el proceso de desarrollo de una marca como una actividad estrechamente vinculada al desarrollo de nuevos productos (Watkins, 1986). Con el transcurso del tiempo, este paradigma se transformó otorgándole al proceso de desarrollo y gestión de la marca una importancia estratégica y no meramente táctica.

De ese modo, el proceso de desarrollo de una marca con sentido estratégico adquirió mayor relevancia y surgieron modelos teóricos que plantean las etapas que involucra. Aunque no todos los modelos abordan las fases del proceso en forma simétrica, existe coincidencia -con variaciones menores- en el hecho que el desarrollo de la estrategia de marca atraviesa las cuatro fases propias del planeamiento estratégico; análisis, desarrollo, ejecución y evaluación final o control. La etapa inicial de análisis estratégico se concentra en comprender la posición competitiva de la marca con el fin de definir de qué modo podría conquistar una posición en el mercado a partir de los atributos de sus productos o servicios y habilidades de la organización, para luego formular el Brand Vision (Davis, 2000) o 'visión de la marca' que establece los anhelos de la marca para el futuro expresados en términos de objetivos, público al que se dirige, rasgos de diferenciación y objetivos financieros. La siguiente fase se centra en el desarrollo de la estrategia de marca, incluyendo el posicionamiento de la marca y la estrategia de comunicación junto con los restantes factores que integran la mezcla de marketing (Davis, 2000). La creación de la identidad de marca -concepto más amplio que precede y engloba el posicionamiento- y la proposición de valor como síntesis de la identidad de marca que propone beneficios de carácter tangible y de carácter imaginario- ambas nociones agregadas por Aaker (2000) a este modelo. En la tercera fase, se plantea la ejecución de la estrategia de comunicaciones integradas -la que incluye publicidad, relaciones públicas, prensa, eventos y actividades promocionales- para instalar la marca en el mercado. La fase final -o cuarta etapa- de evaluación implica la medición del retorno sobre la inversión alcanzado por la marca y su valor en términos de equidad de marca. (Aaker, 2000) 
Es importante remarcar que la estrategia de marca -centro neurálgico del proceso de desarrollo de la marca- proporciona dirección, consistencia y propósito a largo plazo. Sin embargo, al intentar definir con precisión la noción de 'estrategia' desde una concepción de negocios, la tarea no resulta sencilla debido al amplio espectro de perspectivas teóricas existentes. Aunque paradójico en apariencia, es posible que precisamente el amplio espectro de perspectivas sirva para explicar la concepción que el diseño y el marketing adoptan sobre el desarrollo de la estrategia de marca.

La perspectiva más tradicional, que corresponde a la escuela de planificación, que dominó en las publicaciones académicas y las publicaciones de negocios en la década del '50 hasta los años '70, concibe la estrategia como un plan; es decir como un curso de acción trazado para alcanzar una meta predeterminada. La característica esencial del plan es que establece anticipadamente una serie de acciones que luego deberán ser ejecutadas en forma intencional y pautada. Este enfoque se basa en el modelo FODA (fortalezas, oportunidades, debilidades y amenazas) y divide el proceso en etapas claramente delineadas, otorgándole especial importancia a la fijación de objetivos y a la elaboración de planes y presupuestos.

Sin duda se encuentran resonancias entre esta perspectiva teórica y el modo de abordar el proceso de desarrollo de la estrategia de marca planteado más arriba; aunque en una jerarquía menor y en forma posterior a la formulación del plan corporativo, al plan de operaciones y al plan de cada sector. Este modelo refleja en gran medida la realidad de la práctica profesional de los gerentes de marca que, además de abordar la formulación de la estrategia de marca a través de las fases descriptas, fijan objetivos mensurables y presupuestos de inversión publicitaria, proyectando resultados como parte de un enfoque que asigna prioridad a un programa de ejecución altamente formal. Una limitación que presenta este modelo es su falta de previsón de situaciones de incertidumbre que lo tornan inflexible debilitando su posición en el mercado (Mitzberg, 2000).

Desde una ángulo diferente, la escuela de diseño -que se origina en la escuela de negocios de la Universidad de California, el Massachussets Institute of Technology y la Escuela de Negocios de la Universidad de Harvard a fines de los años '50 y principios de los '60- concibe la estrategia como un proceso que intenta compatibilizar la situación interna de la organización con el entorno; en el primer caso para descubrir las oportunidades y amenazas que presenta el contexto, y en el segundo, para definir las fortalezas y debilidades de la organización, asignándole también un papel importante en este plano analítico a las creencias y valores de los directivos de la organización.

Es evidente que la perspectiva estratégica de la escuela de diseño se ve reflejada en el proceso estratégico de desarrollo de la marca. Al encarar la fase de análisis estratégico de la marca este modelo -que diseñadores y profesionales en marketing utilizan en forma compartida- propone partir de un análisis FODA para formular luego la 'Visión' de la marca. Se trata de un enfoque más simple que el modelo de la escuela de planeamiento que proporciona orden y resulta de utilidad en entornos relativamente estables donde sirve de sustento a estilos de liderazgo que proponen una visión sólida para el futuro de la marca. Sin embargo, su simpleza puede resultar insuficiente ante entornos de mayor complejidad y con frecuencia es utilizado en forma complementaria al modelo de planeamiento. (Mintzberg, 2000)

Estos paralelismos permiten descubrir la importancia que adquieren las dos escuelas anteriores como afluentes del modelo de desarrollo estratégico de la marca. Sin embargo, la perspectiva 
teórica que presenta mayor compatibilidad y resonancia con el pensamiento disciplinar del diseño en relación a la estrategia de marca, es la escuela cultural. Esta perspectiva concibe la formulación de la estrategia como un proceso colectivo que refleja la cultura de la organización. Este modelo, originado por autores suecos -Rhenman (1965), Normann (1977) y Jonsson (1977)-, se basó en la antropología para desarrollar un enfoque que permita comprender mejor el crecimiento y el cambio estratégico en una organización. Más adelante, Barney (1991) y Wernerfelt (1995) añadieron a la teoría cultural su análisis sobre la importancia de los recursos de la organización, definiéndolos como los activos, las capacidades, los procesos organizacionales, a la par de sus conocimientos y experiencia. Este enfoque plantea que sólo puede mantenerse una ventaja competitiva cuando ésta se basa en recursos originales que no pueden ser imitados por los competidores y tampoco pueden ser reemplazados por sustitutos.

Criticada por su vaguedad conceptual, Mintzberg et al (2000) advierten que los peligros de esta escuela son: la posibilidad de desalentar el cambio debido al énfasis que colocan en la tradición y el consenso, al igual que la creencia errónea de que la diferenciación o singularidad constituyen por sí mismas una ventaja estratégica. Se trata ésta de una crítica que es válido extrapolar como una falencia común en la formulación de una estrategia de marca que gire en torno a las capacidades o recursos de la organización. No obstante ello, en el escenario corporativo -y en el ámbito de algunas industrias en particular- es factible encontrar organizaciones alineadas detrás de esta corriente de pensamiento que llevan adelante su estrategia con éxito.

En ese sentido, el design management -o gestión de diseño- propone la instauración de una cultura organizacional en la que el diseño desempeñe un papel fundamental como recurso estratégico para alcanzar los objetivos de crecimiento de la organización. Este enfoque concibe el diseño como una función de negocios pero al mismo tiempo contempla el hecho que se trata de una disciplina de naturaleza interdisciplinaria que integra campos disciplinares como el arte, el diseño, el marketing y los negocios.

Desde este paradigma se pueden explicar las nuevas fronteras del branding que imponen una alianza entre el campo disciplinar del diseño y el marketing. El intercambio de saberes y perspectivas teóricas puede contribuir a ampliar la visión estratégica de ambas disciplinas y aportar nuevas ventajas competitivas a la organización. La estrategia de marca, de ese modo, podría ser abordada desde una perspectiva estratégica en la que confluya un enfoque de diseño estratégico con una cultura de diseño en la organización. El nexo conceptual entre ambas quizás dé lugar a la pareja perfecta que anuncie la hora de retirada de las estrategias de torre de marfil. Intuición, creatividad y visión estratégica no tienen por qué ser incompatibles. En todo caso, se trata de combinar y potenciar las habilidades de diseñadores y marketineros para lograr una estrategia de marca que integre en forma efectiva el sistema productor de imágenes con el sistema de representación mental, entrelazando el diseño del producto, la psiquis, la cultura y el análisis del negocio en un sistema cohesivo que resulte en la consolidación de una fuerte equidad de marca.

\section{Referencias Bibliográficas}

Aaker, D. (1996). El éxito de tu producto está en la marca. México: Prentice-Hall.

Borja de Mozota, B. (2003). Design management: using design to build brand value and corporate innovation. New York: Allworth Press. 
Davis, S. (2002). Brand Asset Management: Driving Profitable Growth Through Your Brands. USA: The Jossey-Bass Business \& Management Series.

Mintzberg, H., Ahlstrand, B. y Lampel, J. (1999). Safari a la estrategia: Una visita guiada por la junga del management estratégico. Barcelona: Ediciones Granica.

Valdés de León, G. (2005). Cinco posibles maneras de mirar la imagen. En, XIII Jornadas de Reflexión Académica en Diseño y Comunicación 2005. Formación de Profesionales Reflexivos en Diseño y Comunicación. Facultad de Diseño y Comunicación, Universidad de Palermo. Buenos Aires, pp. 261-269

Watkins, T. (1986). The economics of the brand: A marketing analysis. USA: McGraw-Hill.

\title{
Recursos Electrónicos
}

Business Dictionary. Disponible en: http://www.businessdictionary.com/definition/branding.html

\begin{abstract}
Summary: Branding -creation and strategic management of a brand- gained notoriety in the 90s joining the academic debate and professional activity of the disciplinary field of design and marketing. The fact of being both strategical and tactical caused some confusion about the branding nature. This debate has become in a theoretical reflection on the new territory and explore the activity surrounding the construction of a brand in an attempt to find theoretical perspectives to help understand the process. In doing so, it examines the concept of brand as a production and imaging bipolar system, and explores the stages of brand development in parallel with the strategic planning process. Finally, we analyze the influence of different schools of strategic thinking to discover the new frontiers facing this paradigm.
\end{abstract}

Keywords: brand management design - brand strategy - brand vision - brand visual image branding - marketing - trademark construction.

Resumo: $\mathrm{O}$ branding, anglicismo com o que se denomina à criação e gestão estratégica de uma marca, cobrou notoriedade na década dos ' 90 incorporando-se ao debate acadêmico e à atividade profissional do campo disciplinar do design e o marketing. Este trajeto provocou confusão respeito à natureza -as vezes estratégica e as vezes táctica da atividade. . Este fato dá lugar à reflexão teórica sobre o novo território e a explorar a atividade que rodeia à construção duma marca, num intento por descobrir perspectivas teóricas que ajudem a compreender o processo. Deste modo, se examina a noção de marca como sistema bipolar de produção e projeção de imagens, e se exploram as faces do processo de desenvolvimento da marca em paralelo ao processo de planejamento estratégico. Finalmente, se analisa a influencia que recebe o processo de diferentes escolas de pensamento estratégico para descobrir as novas fronteiras que atravessa este paradigma.

Palavras chave: branding - construção marcaria - estratégia de marca - gestão de design de marca - imagem visual da marca - marketing - visão da marca. 